\title{
Preparation and characterization of polyamide 6 nanocomposites using MWCNTs based on bimetallic Co-Mo/MgO catalyst
}

\author{
A. J. Hassani ${ }^{1}$, Z. A. Mohd Ishak ${ }^{2,3}$, A. R. Mohamed ${ }^{1 *}$ \\ ${ }^{1}$ Chemical Engineering School, Engineering Campus, Universiti Sains Malaysia, Seri Ampangan, 14300 Nibong Tebal, \\ Penang, Malaysia \\ ${ }^{2}$ School of Material and Mineral Resources Engineering, Engineering Campus, Universiti Sains Malaysia, Seri \\ Ampangan, 14300 Nibong Tebal, Penang, Malaysia \\ ${ }^{3}$ Cluster for Polymer Composites, Science and Engineering Research Centre, Engineering Campus, Universiti Sains \\ Malaysia, Seri Ampangan, 14300 Nibong Tebal, Penang, Malaysia
}

\begin{abstract}
Multiwalled carbon nanotubes (MWCNTs) based on bimetallic $\mathrm{Co}-\mathrm{Mo} / \mathrm{MgO}$ catalyst were produced in large scale by catalytic chemical vapor deposition method (CCVD) of methane. X-ray diffraction (XRD), transmission electron microscopy (TEM), thermogravimetric analysis (TGA) and Raman spectroscopy proved carbon nanotube (CNT) formation. As-produced multiwalled carbon nanotubes (PCNTs) and commercial ones (CCNTs) with the same diameter (10$20 \mathrm{~nm}$ ) were melt blended with polyamide 6 (PA6). XRD patterns of nanocomposites showed applying $0.1 \%$ of both types of CNTs changed the crystalline structure of neat PA6 from $\alpha / \gamma$ form to thermodynamically more stable $\alpha$-phase structure. Differential scanning calorimetry (DSC) showed both types of CNTs shifted crystallization temperature of about $10-15^{\circ} \mathrm{C}$ to higher temperature due to the nucleating effect of nanotubes. Furthermore, degree of crystallinity increased by about $30 \%$ in some composites, especially for PCNTs. Nanocomposites containing PCNTs exhibited improvements in thermal decomposition temperature in comparison with CCNT nanocomposites. Nanocomposites melt viscosity increased at high CNTs loading due to the filler-matrix entanglements.
\end{abstract}

Keywords: nanocomposites, mechanical properties, thermal properties, carbon nanotube, polyamide

\section{Introduction}

MWCNTs with extraordinary mechanical, electrical and thermal properties were first ever observed by Iijima [1]. Nowadays, several different processes such as chemical vapour deposition (CVD) of hydrocarbons, arc discharge, laser ablation, solar carbon vaporization and carbon electrode electrolysis in ionic salts melts are employed to prepare CNTs. Large quantity production of CNTs with high quality and selective diameter and length is the main challenge in carbon nanotube technology. Decomposition of hydrocarbons over transition metals or their compound at the moderate temperatures is one of the simplest routes to prepare CNTs in large scale and low cost. Crystalline quality and defects on the individual CNTs affect CNTs properties. Commonly, the CVD process yields a lot of entanglements in the resulting CNTs in comparison to other methods. Because of the large surface area, high aspect ratio and above-mentioned properties, CNTs are one of the best candidates for reinforcing phase in polymeric matrices. In situ polymerization [2], solution casting [3] and melt processing [4] are applied to distribute and disperse CNTs in thermoset and/or

\footnotetext{
${ }^{*}$ Corresponding author, e-mail: chrahman@eng.usm.my

(C) BME-PT
} 
thermoplastic based nanocomposites. Semi-crystalline engineering thermoplastic PA6 is used in many applications, i.e. automotive, aerospace, textiles, electrical and electronics industries. PA6/nanoclay nanocomposites have been investigated intensively in the last decade [5]. In addition, recently, the number of investigations on CNT/PA nanocomposites including modified and unmodified CNTs is increasing. Several researches have also been reported considering different aspects of thermal, mechanical, electrical and rheological properties of nanocomposites which have used in situ polymerization, solution casting, melt spinning and melt compounding methods [3, 4, 6-9].

Melt mixing of CNTs and thermoplastic matrices by single screw $[10,11]$ or twin screw extruder $[6$, 12-14] is the most economical and desirable approach in comparison with other methods because, for fabricating these composites no additional equipment is needed. This process can be performed with conventional plastic machines, i.e. injection molding and extrusion. In addition, for large-scale production of carbon nanotube composites, in situ polymerization needs new mixing and conveying technology in upstream production lines and in some cases change of reactor type and its design would be required. In solution method, a lot of solvents are necessary and recovery of solvent and contaminants in the final product can affect the properties of the product. However, in some cases there would be no any other method to obtain a desired product.

Rangari et al. [10] reported that the tensile strength of PA6 fibre nanocomposites prepared by a single screw extruder, enhanced by $230 \%$ which contained only $1 \mathrm{wt} \%$ unmodified CNTs, while De Zhang et al. [6] indicted that tensile strength improved by about $124 \%$ with the same CNTs loading using twin - screw mixer. Phang et al. [14] have studied the effect of CNTs on crystallinity of the polymer matrix prepared via melt compounding. They found that CNTs changed polymer crystalline structure and $\alpha$-phase crystalline structure forms independently from cooling rate and annealing conditions. This behaviour is completely different from PA/nanoclay nanocomposites. Sun et al. [15] have compared different nanoparticles behaviour in PA6. They found that different nanoparticles change the crystallization temperature peak to higher temperature due to nucleating effect of montmorillonite, $\mathrm{SiO}_{2}$ and
CNTs. They have also reported that CNTs induce $\alpha$ phase crystalline structure.

Our research group has been working on the synthesis of CNT for several years [16-18] and have synthesized MWCNTs with different aspect ratios and purity on various catalysts. Specifically, recently, we have produced CNT on a pilot plant scale [19]. In the present study, MWCNTs were produced using the catalytic chemical vapor deposition (CCVD) method on bimetallic Co-Mo/MgO catalyst in a rotary tubular reactor. PA6/CNT nanocomposites at different loading of CNTs have been prepared by melt mixing technique. The focus has been on investigating and comparing the effect of as-produced CNTs and commercial ones on mechanical, rheological, morphological and thermal properties of the PA6 matrix.

\section{Material and methods \\ 2.1. Materials}

PA6 pellets (CM1017-Toray, Japan) were used in this study. The melt flow index (MFI at $230^{\circ} \mathrm{C}$ and $2.16 \mathrm{~kg}$ load) and density of PA6 were $35 \mathrm{~g} / 10 \mathrm{~min}$ and $1.14 \mathrm{~g} / \mathrm{cm}^{3}$, respectively. Commercial MWCNTs with $\sim 95 \%$ purity were purchased from Shenzhen Nanotech Port Co. Ltd (NTP), China. The diameter, length, special surface area and thermal conductivity of CCNT were $10-20 \mathrm{~nm}, 5-15 \mu \mathrm{m}, 40-300 \mathrm{~m}^{2} / \mathrm{g}$ and $\sim 2000 \mathrm{~W} /(\mathrm{m} \cdot \mathrm{K})$, respectively. Ammonium molybdate tetrahydrate, citric acid, cobalt(II) nitrate and magnesium nitrate were purchased from a local supplier, Kumpulan Saintifik F.E. Sdn, Bhd. (KSFE), Malaysia.

\subsection{Carbon nanotube preparation}

The MWCNTs were prepared by chemical vapor deposition of methane on bimetallic $\mathrm{Co}-\mathrm{Mo} / \mathrm{MgO}$ catalyst [19]. Briefly, materials were accurately weighed and dissolved in a proper amount of water and mixed at $90^{\circ} \mathrm{C}$ to form a purple gel. After that, the gel was dried at $120^{\circ} \mathrm{C}$ overnight. Foamed material was ground in a mortar, and it was calcined at $700^{\circ} \mathrm{C}$ for two hours. Prepared catalysts were sieved and were used to prepare MWCNTs. Then, the catalyst was continuously fed into the rotary reactor system and the reaction occurred in the reactor tube at $800^{\circ} \mathrm{C}$. A residence time of $1 \mathrm{hr}$ was chosen by screw conveyor speed controlling. Deposited carbonaceous material on the catalyst was collected in the reservoir that fixed at the end of the reactor. 


\subsection{Nanocomposite preparation}

PA6 and two types of CNTs were dried at $80^{\circ} \mathrm{C}$ for $15 \mathrm{~h}$ before melt compounding. Melt blending was performed on a single screw extruder (Brabender KE19/25 D) at $35 \mathrm{rpm}$ in different CNT loadings for both types of CNTs. Operating temperatures at different zones from the hopper to die were 225, 230, 235 and $230^{\circ} \mathrm{C}$ respectively. Nanocomposites were obtained with CCNTs and PCNTs at 0.1, 0.2, $0.5,1,2$ and $3 \mathrm{wt} \%$ loading. After melt mixing, nanocomposites of $1 \mathrm{~mm}$ thickness were prepared by compression molding at $250^{\circ} \mathrm{C}$ and 100 bars by using a Gotech KT-7014A press. Prior to hot press, samples were put in the vacuum for $15 \mathrm{~h}$ at $80^{\circ} \mathrm{C}$.

\subsection{Differential scanning calorimetry (DSC)}

Differential scanning calorimetry experiments were performed by a Mettler Toledo DSC-1 instrument using Stare software under nitrogen atmosphere. Samples of about $10 \mathrm{mg}$ were accurately weighed and placed in an aluminium pan. Then the pan was heated from 25 to $250^{\circ} \mathrm{C}$ at a heating rate of $10^{\circ} \mathrm{C} / \mathrm{min}$. Prior cooling to room temperature samples were maintained for $4 \mathrm{~min}$ at $250^{\circ} \mathrm{C}$ to erase previous thermal history. Then, the cooling was done at the same heating rate from $250^{\circ} \mathrm{C}$ to room temperature. This process was performed for another cycle, and data was recorded for the last cycle.

Crystallinity content can be calculated using Equation (1) [20]:

$X_{\mathrm{c}}=\frac{\Delta H_{\mathrm{f}}}{\Delta H_{\mathrm{f}}^{0} \omega_{\mathrm{PA} 6}} \times 100$

where $\Delta H_{\mathrm{f}}^{0}$ is heat of fusion $[\mathrm{J} / \mathrm{g}]$ for a theoretical completely (100\%) crystalline PA6, reported in the literature to be about $190.8 \mathrm{~J} / \mathrm{g}$ [21], $\Delta H_{\mathrm{f}}$ is the experimentally measured fusion heat of nanocomposite by DSC and $\omega_{\mathrm{PA} 6}$ is the PA6 weight fraction in the nanocomposites.

\subsection{X-ray Diffraction (XRD)}

XRD measurements of the nanocomposites, neat PA6, PCNTs and CCNTs were carried out in reflection mode with a D5000 diffractometer (Siemens) using $\mathrm{CuK}_{\alpha}$ radiation at a scan rate of $0.3^{\circ} / \mathrm{min}$ in a $2 \theta$ range of $10-30^{\circ}$, and operated at $20 \mathrm{~mA}$ and $30 \mathrm{kV}$.

\subsection{Mechanical properties}

Tensile samples were punched from sheets according to ASTM D638 type IV. The testing with a cross-head speed of $50 \mathrm{~mm} / \mathrm{min}$ was carried out on an Instron 3367 universal testing machine to measure tensile modulus, strength and elongation at break. All samples were dried at $80^{\circ} \mathrm{C}$ for $15 \mathrm{~h}$ prior to testing.

\subsection{Thermogravimetric analysis}

TGA (TA Instrument, SDT Q600) was done for CCNTs, PCNTs, neat PA6 and prepared nanocomposites, both in air and nitrogen atmosphere from room temperature up to $700^{\circ} \mathrm{C}$. Heating rate of $10^{\circ} \mathrm{C} / \mathrm{min}$ was chosen.

\subsection{Melt flow index}

MFI was performed in the Dynisco Melt Flow Indexer according to ASTM D1238 $\left(235^{\circ} \mathrm{C}\right.$ and $1 \mathrm{~kg}$ ). All samples were dried at $80^{\circ} \mathrm{C}$ for $15 \mathrm{~h}$ before rheological measurements.

\section{Results and discussion}

\subsection{Carbon nanotube characterization}

Figure 1a shows TEM image of PCNTs obtained on the bimetallic catalyst. It can be seen that deposited materials are rope-like carbon nanostructures with hollow core, and their average diameters are about 10-20 nm. TGA profiles of PCNTs and CCNTs are shown in Figure 1b. It can be seen that about $60 \%$ carbonaceous materials are grown on the catalyst in the final product. Amorphous carbon content is about $5 \%$ (loss weight at about $350^{\circ} \mathrm{C}$ ). High thermal stability $\left(>500^{\circ} \mathrm{C}\right)$ confirms the carbon nanotube formation. TGA reveals that PCNTs are more thermodynamically stable than CCNTs and their decomposition temperature is at least $60^{\circ} \mathrm{C}$ higher than CCNTs. Raman spectroscopy of PCNTs (Figure 1c) shows two main peaks at 1594 and $1326 \mathrm{~cm}^{-1}$. The $1585 \mathrm{~cm}^{-1}$ peak corresponds to G-band characteristic feature of the graphitic layers that are related to the tangential vibration of the $\mathrm{sp}^{2}$ carbon atoms. The second peak is a typical sign for defective graphitic structures (D-band). G-band and D-band peaks for CCNTs are at 1595 and $1332 \mathrm{~cm}^{-1}$, respectively. Generally, D to $\mathrm{G}$ band intensity ratio $\left(I_{\mathrm{D}} / I_{\mathrm{G}}\right)$ is used as a criterion for quality determination of 
synthesized CNT. The higher ratio shows more amorphous carbon on the surface of CNTs and/or more disorders in carbon nanotubes. $I_{\mathrm{D}} / I_{\mathrm{G}}$ of PCNTs and CCNTs were 1.54 and 1.37 respectively. Higher value for PCNTs arises from more amorphous carbon which can be seen in the DTG curve between 300 to $400^{\circ} \mathrm{C}$. Oxidation of PCNTs in the air for $2 \mathrm{hr}$ reduced D-band to G-band intensity to 1.17 which shows amorphous carbon can strongly influence the intensity of disorder band in the CNTs.

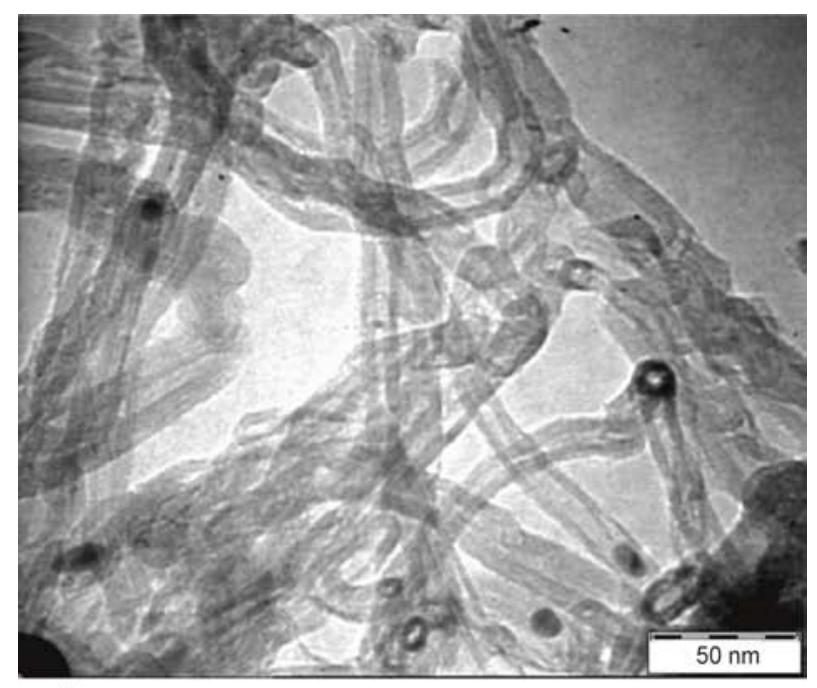

a)
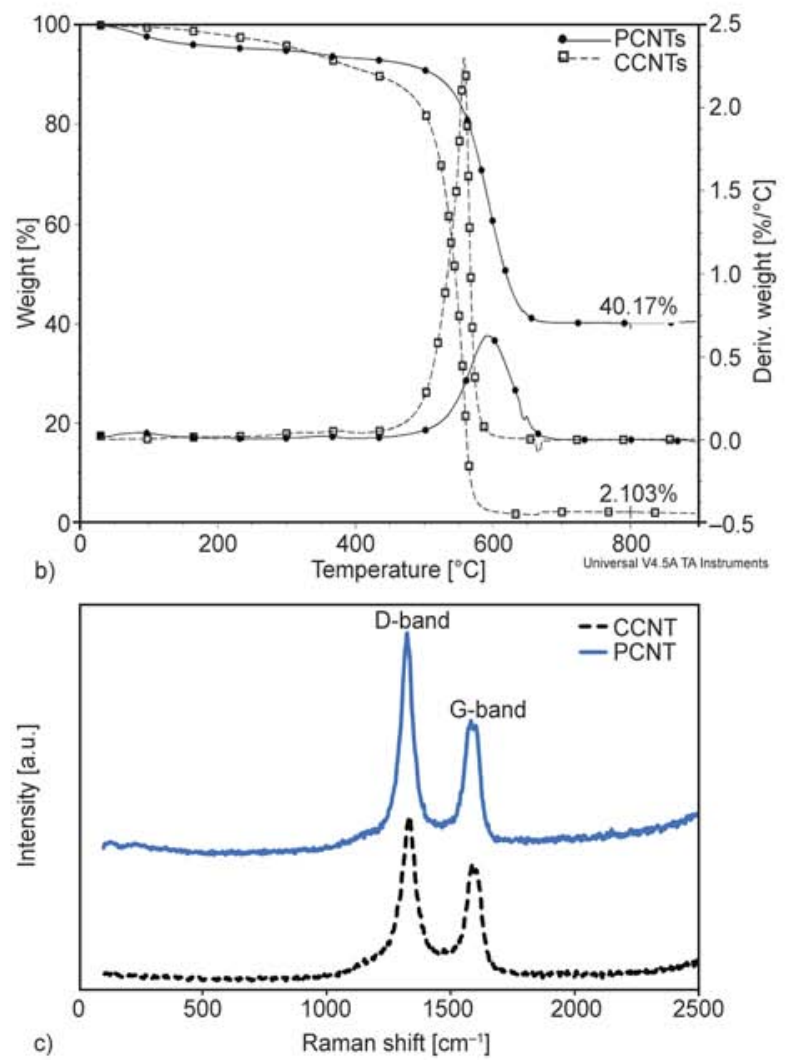

Figure 1. a) TEM of PCNTs, b) TGA curves, and c) Raman spectra of PCNTs and CCNTs

\subsection{Nanocomposite properties}

Crystallization behaviour of neat PA6 and its nanocomposites were studied to analyze MWCNTs effect in the PA6 matrix. The cooling process used in this study is similar to the real manufacturing process, i.e. injection moulding, extrusion and fibre spinning. Figure 2 shows cooling and heating curves for PA6 and its composites. Crystallization peak and its onset, melting peak and its onset as well as the degree of crystallinity are presented in Table 1 . It can be seen that with increasing both PCNTs and CCNTs loading in composite, crystallization peak is shifted to higher temperatures. This indicates that CNTs act as nucleating agents in the polymer matrix. It can be also seen with increasing both types of CNTs in the continuous phase, more heterogeneous nucleation sites are available, and hence more polymer chains are induced to crystallize. Indeed more CNTs in polymer increase crystallization temperature. The degree of crystallinity is significantly increased by using $0.2 \%$ of carbon nanotube for both types of CNTs. The reduction in the degree of crystallinity with the CNT loading of more than $0.2 \%$ implies that CNTs could act as an efficient nucleating agent at low concentrations. Their nucleating ability gradually reduced at high content. However, it is worth mentioning that the degree of crystallinity of nanocomposites at high CNT loadings is still more than neat PA6 indicating the occurrence of the nucleation process at high CNT content. Randomly dispersed MWCNs at higher concentrations can restrict

Table 1. Melting peak $\left(T_{\mathrm{m}}\right)$ and its onset, crystallization peak $\left(T_{\mathrm{c}}\right)$ and its onset and, crystallinity percent of neat PA 6 and nanocomposites

\begin{tabular}{|c|c|c|c|c|c|}
\hline \multirow{2}{*}{ Samples } & \multicolumn{2}{|c|}{$T_{m}$} & \multirow{2}{*}{$\underset{[\%]}{\mathbf{X}_{\mathbf{m}}{ }^{*}}$} & \multicolumn{2}{|c|}{$T_{c}$} \\
\hline & Onset & Peak & & Onset & Peak \\
\hline PA 6 & 207.0 & 221.1 & 30.3 & 186.4 & 181.0 \\
\hline CCNT-0.1\% & 208.3 & 220.5 & 30.5 & 197.4 & 192.7 \\
\hline CCNT- $0.2 \%$ & 207.9 & 220.5 & 37.2 & 198.6 & 193.3 \\
\hline CCNT- $0.5 \%$ & 207.6 & 220.6 & 37.3 & 200.2 & 193.9 \\
\hline CCNT-1\% & 206.9 & 220.8 & 32.9 & 201.7 & 193.8 \\
\hline CCNT-2\% & 206.4 & 220.6 & 34.8 & 202.7 & 194.4 \\
\hline CCNT-3\% & 205.9 & 220.5 & 31.2 & 203.8 & 195.1 \\
\hline PCNT- $0.1 \%$ & 207.6 & 220.6 & 38.4 & 199.4 & 193.5 \\
\hline PCNT- $0.2 \%$ & 207.5 & 221.3 & 60.0 & 200.6 & 193.7 \\
\hline PCNT- $0.5 \%$ & 207.7 & 220.8 & 41.1 & 200.7 & 193.9 \\
\hline PCNT-1\% & 207.3 & 220.3 & 39.3 & 202.2 & 194.8 \\
\hline PCNT- $\%$ & 206.7 & 221.0 & 49.4 & 203.8 & 195.1 \\
\hline PCNT-3\% & 206.7 & 220.9 & 38.0 & 204.6 & 195.7 \\
\hline
\end{tabular}

*Normalized crystallinity according to Equation (1) 

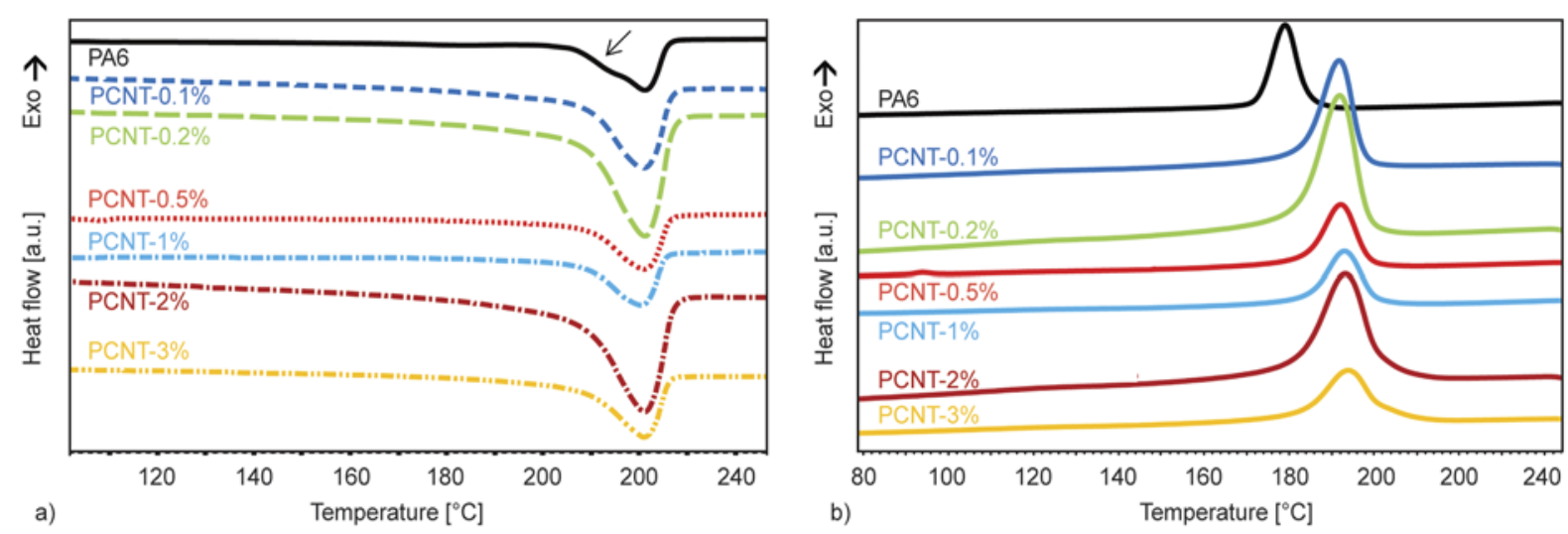

Figure 2. DSC thermograms of neat PA6 and its nanocomposites containing different loadings of PCNTs; a) heating curves, b) cooling curves

crystals and thus the crystal growth rate will be retarded [22].

Table 1 shows that PCNTs possessed a relatively higher degree of crystallinity than CCNTs. This may be attributed to better interaction between the catalyst in PCNTs and the polar amide group in PA6 chains. Another possible reason is the existence of more entanglement in PCNTs in comparison to CCNTs according to higher D-band to G-band intensities that could act as nodes to make more nucleating agents and consequently, such nodes can increase the degree of crystallinity. Melting point temperature will decrease at high content CNTs because of high thermal conductivity of CNTs that facilitate heat transfer into the crystalline parts and hence melting would happen at a lower temperature. Neat PA6 shows a broader peak and a small shoulder around $215^{\circ} \mathrm{C}$ which corresponds to $\gamma$-crystalline form. This is in agreement with the observation obtained by XRD that will be discussed later.

The XRD spectra of PA6, PCNTs, CCNTs and all nanocomposites are presented in Figure 3. It can be

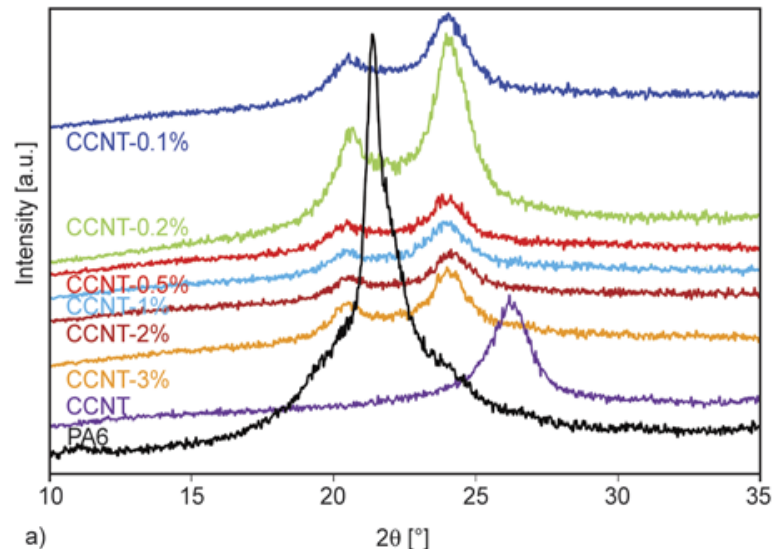

seen neat PA6 has a sharp peak at $21.4^{\circ}$ that corresponds to pseudohexagonal $\gamma$-crystalline form as dominant phase and two short shoulders at approximately $2 \theta=20$ and $23.7^{\circ}$ for the $\alpha$-crystalline form [23]. For both types of the CNTs (002) diffraction plane is observed at around $2 \theta \cong 26^{\circ}$ that confirms graphitic planes in their structure [24, 25]. Two main peaks are observed for all 12 nanocomposites at about $2 \theta=20.5^{\circ} \pm 0.1$ and $2 \theta=23.9^{\circ} \pm 0.1$ where correspond to (200), (002) and (220) [26, 27] or (100), (010) and (110) [28] reflections which are characteristic of the $\alpha$-crystalline form. These peaks depict induced $\alpha$-form crystalline microstructure by PCNTs and CCNTs in the nanocomposites. It is known that structure changing of material affects physical and mechanical properties. Here, metastable $\gamma$-crystalline form involving orderless hydrogen bonding among parallel chains in neat PA6 is converted to more thermodynamic stable $\alpha$-from that includes sheets of hydrogen-bonded chains created between antiparallel chains by adding both types of CNTs. Indeed this behaviour is different from the normally reported

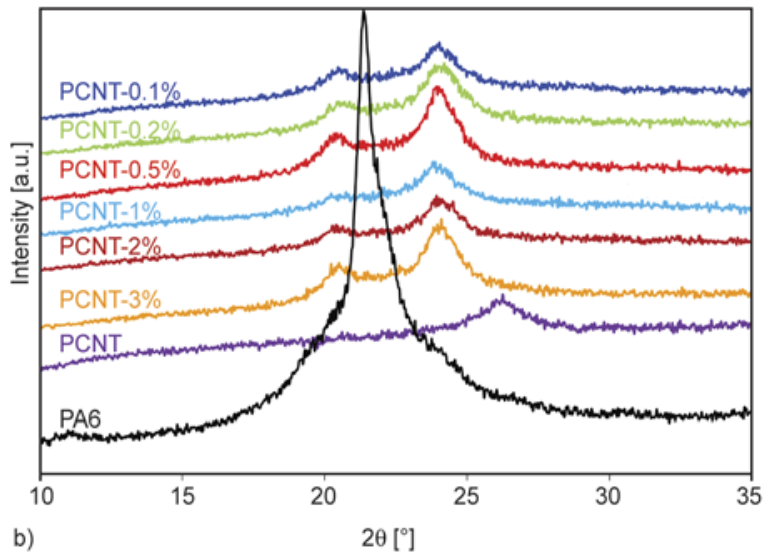

Figure 3. a) XRD patterns of PA6, CCNTs and their nanocomposites; b) XRD patterns of PA6, PCNTs and their nanocomposites 
data for PA6/nanoclay nanocomposites [29]. Liu et al. [4] have presented the same observation in polyamide filled MWCNTs. They proposed that polymer chain movement in the presence of onedimensional CNT is less restricted compared with two-dimensional nanoclays. Therefore, CNTs may only act as the nucleation agent for PA6 chains to create $\alpha$-crystalline form. Thus, CNTs have nucleating effect in the polymer matrix. It can be seen that a small amount of CNTs (only $0.1 \%$ ) increased crystallinity and changed the morphology of the polymer matrix from metastable $\gamma$-form crystal to thermodynamically stable $\alpha$-form and thus, better mechanical or physical properties would be expected. Indeed CNTs change the kinetics of crystallization and this leads to a different degree of crystallinity and crystals dimensions.

Figure 4 shows the TGA behaviour of neat PA6 and its nanocomposites under air and nitrogen. Onset decomposition temperature $\left(T_{5 \mathrm{wt} \%}\right)$ and maximum degradation temperature for neat PA6 and its nano-

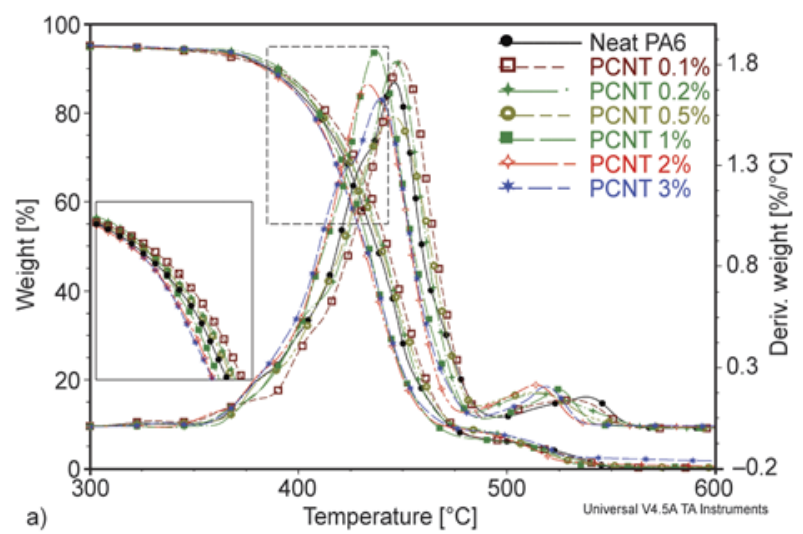

composites under air and nitrogen atmosphere are presented in Table 2.

Thermal behaviour under air and nitrogen atmosphere is the same for nanocomposites and pure PA6. Decomposition of PA6 and nanocomposites containing PCNTs under air (Figure 4a) displayed a two-stage decomposition. The maximum decomposition temperatures for these two stages are summarized in Table 2. A slight change can be seen in first stage. Also, a small decreasing of decomposition temperature in second stage is observed for both types of CNT nanocomposites. This behaviour can be attributed to the high thermal conductivity of CNTs. Decomposition temperature at $5 \mathrm{wt} \%$ under $\mathrm{N}_{2}$ atmosphere (Figure $4 \mathrm{~b}$ ) has been enhanced with the increasing CNTs loading. As can be seen in Table 2, thermal stability enhancement of the PA6 matrix by PCNTs is better than CCNTs. Different catalyst types, carbon nanotube heat capacity, thermal conductivity, volume fraction, aspect ratio, orientation and packing of the filler material can affect thermal

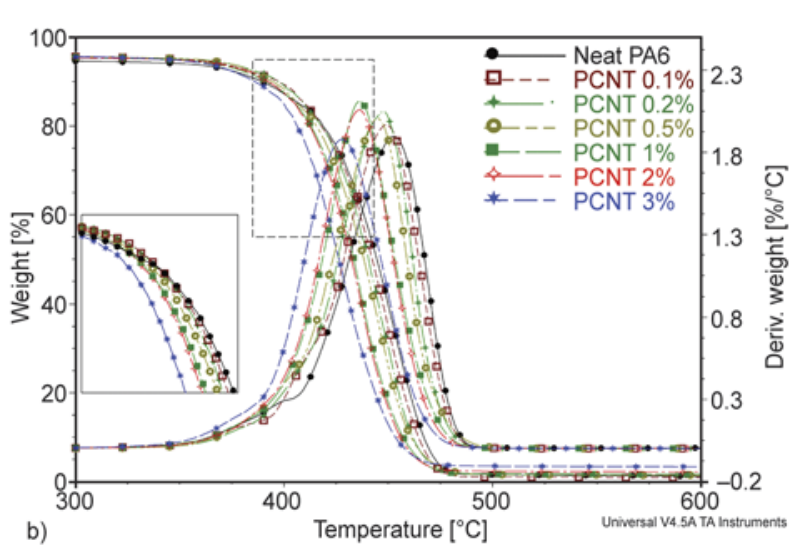

Figure 4. TGA and DTG curves of PA6 and PA6/PCNTs nanocomposites; a) under air, b) under nitrogen

Table 2. Decomposition temperature for 5, 10\% weight loss and residue in air and nitrogen atmosphere and their maximum peaks

\begin{tabular}{|c|c|c|c|c|c|c|c|c|c|}
\hline \multirow[b]{2}{*}{ Samples } & \multicolumn{5}{|c|}{ Air environment } & \multicolumn{4}{|c|}{$\mathbf{N}_{2}$ environment } \\
\hline & $\begin{array}{c}5 \mathbf{w t} \% \\
{\left[{ }^{\circ} \mathrm{C}\right]}\end{array}$ & $\begin{array}{c}10 \mathrm{wt} \% \\
{\left[{ }^{\circ} \mathrm{C}\right]}\end{array}$ & $\begin{array}{c}\max 1 \\
{\left[{ }^{\circ} \mathrm{C}\right]}\end{array}$ & $\begin{array}{c}\max 2 \\
{\left[{ }^{\circ} \mathrm{C}\right]}\end{array}$ & $\begin{array}{c}\text { Residue at } 600^{\circ} \mathrm{C} \\
{[\%]}\end{array}$ & $\begin{array}{c}5 \mathbf{w t} \% \\
{\left[{ }^{\circ} \mathrm{C}\right]}\end{array}$ & $\begin{array}{c}10 \mathrm{wt} \% \\
{\left[{ }^{\circ} \mathrm{C}\right]}\end{array}$ & $\begin{array}{l}\max \\
{\left[{ }^{\circ} \mathrm{C}\right]}\end{array}$ & $\begin{array}{c}\text { Residue at } 600^{\circ} \mathrm{C} \\
{[\%]}\end{array}$ \\
\hline PA 6 & 307.1 & 385.1 & 447.6 & 540.7 & 0.5 & 246.2 & 389.6 & 453.0 & 1.2 \\
\hline CCNT- $0.1 \%$ & 266.4 & 386.3 & 446.6 & 523.4 & 0.1 & 321.1 & 392.2 & 452.1 & 0.9 \\
\hline CCNT- $0.2 \%$ & 326.9 & 384.2 & 446.6 & 523.4 & 0.1 & 305.4 & 394.7 & 451.9 & 0.9 \\
\hline CCNT- $0.5 \%$ & 292.8 & 388.2 & 445.4 & 539.0 & 0.3 & 337.9 & 397.6 & 454.4 & 0.9 \\
\hline CCNT-1\% & 307.1 & 384.9 & 447.0 & 535.0 & 0.5 & 324.1 & 395.6 & 453.9 & 1.4 \\
\hline CCNT-2\% & 358.0 & 399.9 & 448.4 & 521.9 & 0.5 & 337.5 & 394.5 & 453.5 & 2.0 \\
\hline CCNT-3\% & 299.8 & 389.5 & 450.5 & 500.3 & 0.5 & 332.1 & 393.5 & 455.1 & 3.2 \\
\hline PCNT- $0.1 \%$ & 316.0 & 386.8 & 449.8 & 531.4 & 0.2 & 354.2 & 397.6 & 449.7 & 0.9 \\
\hline PCNT- $0.2 \%$ & 298.7 & 391.8 & 446.0 & 516.1 & 0.2 & 356.1 & 397.8 & 443.9 & 1.4 \\
\hline PCNT- $0.5 \%$ & 326.9 & 393.3 & 448.3 & 519.3 & 0.2 & 359.9 & 394.7 & 445.9 & 1.4 \\
\hline PCNT-1\% & 285.6 & 388.7 & 437.2 & 526.8 & 0.4 & 343.8 & 392.2 & 436.8 & 1.6 \\
\hline PCNT-2\% & 291.4 & 383.3 & 429.7 & 516.0 & 0.5 & 345.6 & 392.3 & 437.9 & 2.2 \\
\hline PCNT-3\% & 324.5 & 386.1 & 439.2 & 521.1 & 1.7 & 344.9 & 386.1 & 429.1 & 3.3 \\
\hline
\end{tabular}


behaviour of nanocomposites. However, after decomposition initiation, nanocomposites including PCNTs show lower degradation temperature which depends on PCNTs loading. At lower temperatures, CNTs act as heat conductive material and pass heat from the nanocomposite core to the outer surface. Therefore, the polymer chain degradation would be retarded. On the other hand, when activation energy is enough to decompose PA6, CNTs conduct heat of decomposition to other parts through the polymer matrix. In this case, nanocomposite would degrade at lower temperatures. This decomposition temperature at different PCNTs loading in constant weight loss in the range of 20 to $80 \%$ can be estimated from linear Equation (2):

$T=\alpha \cdot \omega_{\mathrm{PCNT}}+\beta$

where $T$ is the nanocomposite decomposition temperature in ${ }^{\circ} \mathrm{C}$ and $\omega_{\mathrm{PCNT}}$ is PCNT weight percent in nanocomposites. Parameters $\alpha$ and $\beta$ are constants obtained from degradation curves at constant weight loss. Here, parameter $\alpha$ is calculated as $-5.4115^{\circ} \mathrm{C}$ and $\beta$ is the decomposition temperature of neat PA6 at certain weight loss. This parameter $(\beta)$ for $50 \%$ weight loss is $442.07^{\circ} \mathrm{C}$.

As it is known incorporating MWCNTs in the polyamide matrix will increase the melt viscosity of the polymer melt and as a result, MFI will decrease [22, 30, 31]. MFI for neat PA6 and its nanocomposites are presented in Table 3. A slight increase in MFI of neat PA6 is observed for low CCNT loading. A similar behavior has been reported by Shen et al. [30]. At low CNTs concentrations MFI would not change. Even so, in high CNTs loading, MFI is decreased for both types of CNTs. This may be due to the fact that in low CNTs content, polymer chains can move easily and probably CNTs facilitate polymer chain movement due to non-polar CNTs nature. In this case CNTs could act as a barrier and hinder polar-polar interaction (i.e. hydrogen bonding) between PA6 chains. As a result hydrogen bonding will decrease among polymer chains and polymer movement take place easily. As mentioned before, MWCNTs are in entangled and rope like form. These entanglements can wrap with polymer chains and form larger entanglements. Thus the polymer chain movement in the molten state will be decreased and consequently, melt viscosity will increase. This is in agreement with the degree of
Table 3. MFI of PA6 and its nanocomposites containing PCNTs and CCNTs in different CNTs loading

\begin{tabular}{|l|c|}
\hline \multicolumn{1}{|c|}{ Sample names } & $\begin{array}{c}\text { MFI } \\
{[\mathbf{g} / \mathbf{1 0} \text { min] }}\end{array}$ \\
\hline Neat PA6 & $23.9 \pm 0.9$ \\
\hline CCNT 0.1\% & $24.4 \pm 0.4$ \\
\hline CCNT 0.2\% & $25.0 \pm 1.7$ \\
\hline CCNT 0.5\% & $25.0 \pm 0.7$ \\
\hline CCNT 1\% & $21.5 \pm 1.5$ \\
\hline CCNT 2\% & $19.8 \pm 1.1$ \\
\hline CCNT 3\% & $14.6 \pm 3.3$ \\
\hline PCNT 0.1\% & $23.4 \pm 0.6$ \\
\hline PCNT 0.2\% & $23.3 \pm 0.5$ \\
\hline PCNT 0.5\% & $19.7 \pm 0.5$ \\
\hline PCNT 1\% & $18.8 \pm 0.9$ \\
\hline PCNT 2\% & $19.0 \pm 2.8$ \\
\hline PCNT 3\% & $18.8 \pm 4.2$ \\
\hline
\end{tabular}

crystallinity results as discussed earlier. Degree of crystallinity decreases with increasing CNTs loading more than $1 \%$ that shows nucleating sites are reduced among polymer chains. It can be resulted that CNTs form agglomerates and their dispersion is not desirable in the polymer matrix.

Mechanical properties of PA6 and its nanocomposite are summarized in Table 4. It can be seen that elongation at break, which is known as toughness/ flexibility of the material, drastically decreased by adding both types of unmodified MWCNTs to the PA6. It is known that elongation at break can be reduced by the addition of stiff filler to the polymer matrix. Moreover, the reduction in elongation at break may be due to CNTs aggregation in the PA6 matrix that behaves like physical cross-linked points between individual CNTs. These aggregations can confine the PA6 chains mobility and consequently, reduce elongation at break of nanocomposites. It is worth mentioning that elongation at break of PCNTs nanocomposites at low content loading is higher than that of CCNTs nanocomposites. This may be due to better dispersion of PCNTs in the PA6 matrix in low concentrations that is in agreement with higher tensile strength, modulus and crystallinity. Mechanical properties of CNT composites are affected by the dispersion, orientation and aspect ratio of CNTs. The tensile strength did not increase in the presence of both types of CNTs in the polymer matrix. The rather poor reinforcement effect of CNT may be attributed to undesirable dispersion on CNTs in the matrix i.e. high surface energy of CNTs leads them to form agglomerates. These compact agglomerates lead to inhomogeneous dispersion and stress con- 
Table 4. Summary of mechanical properties of neat PA 6 and its nanocomposite containing PCNTs and CCNTs

\begin{tabular}{|l|c|c|c|}
\hline \multicolumn{1}{|c|}{ Samples } & $\begin{array}{c}\text { Tensile } \\
\text { modulus } \\
{[\mathbf{M P a}]}\end{array}$ & $\begin{array}{c}\text { Tensile } \\
\text { strength } \\
{[\mathbf{M P a}]}\end{array}$ & $\begin{array}{c}\text { Elongation at } \\
\text { break } \\
{[\%]}\end{array}$ \\
\hline PA 6 & $1557 \pm 106$ & $75 \pm 1$ & $28.5 \pm 12.1$ \\
\hline CCNT-0.1\% & $1540 \pm 161$ & $63 \pm 7$ & $5.7 \pm 2.6$ \\
\hline CCNT-0.2\% & $1599 \pm 139$ & $69 \pm 5$ & $9.2 \pm 5.5$ \\
\hline CCNT-0.5\% & $1496 \pm 169$ & $67 \pm 8$ & $6.4 \pm 3.4$ \\
\hline CCNT-1\% & $1669 \pm 111$ & $64 \pm 14$ & $5.8 \pm 5.3$ \\
\hline CCNT-2\% & $1675 \pm 48$ & $65 \pm 15$ & $4.1 \pm 1.4$ \\
\hline CCNT-3\% & $1670 \pm 45$ & $54 \pm 10$ & $2.8 \pm 0.4$ \\
\hline PCNT-0.1\% & $1650 \pm 8$ & $73.0 \pm 0.2$ & $20.0 \pm 7.1$ \\
\hline PCNT-0.2\% & $1638 \pm 110$ & $71 \pm 3$ & $13.9 \pm 7.6$ \\
\hline PCNT-0.5\% & $1390 \pm 36$ & $66 \pm 3$ & $4.3 \pm 0.4$ \\
\hline PCNT-1\% & $1603 \pm 131$ & $61 \pm 20$ & $3.8 \pm 1.5$ \\
\hline PCNT-2\% & $1556 \pm 128$ & $66 \pm 6$ & $3.5 \pm 0.4$ \\
\hline PCNT-3\% & $1642 \pm 22$ & $58 \pm 1$ & $3.0 \pm 0.0$ \\
\hline
\end{tabular}

centration sites in the polymer matrix [32]. In addition, lack of any chemical or hydrogen bonding between CNTs and matrix could be another possible reason. As it is known, CNTs without modification have smooth surface and the absence of functional groups (such as $\mathrm{OH}, \mathrm{COOH}$ and $\mathrm{NH}$ ) on their surface will have poor interaction with the polymer matrix [33]. It seems that the presence of polarity such as CONH group in PA6 alone is still not capable of forming good CNT-PA6 interactions. This may explain the inferior strength of the PA6/CNT nanocomposites as observed in this study. As has been reported in different studies, in order to increase interaction between CNTs and polymers, chemical functionalization of CNTs is performed [34-36]. On the other hand, one of the interesting properties of CNTs is their electrical properties. These will be the outline of our future publications. Tensile modulus has a small increase due to the addition of CNTs to the polymer matrix. This increase was about 6 and $8 \%$ for PA6/PCNTs- $0.1 \%$ and PA6/CCNTs-2\%, respectively.

\section{Conclusions}

In this work, we have prepared bulk MWCNTs based on bimetallic $\mathrm{Co}-\mathrm{Mo} / \mathrm{MgO}$ catalyst in a rotary tubular reactor. As-produced CNTs characterized by using TEM, TGA and Raman spectroscopy. Their thermal stability was better than commercial ones but they are not fully graphitized according to Raman spectrum $\left(I_{\mathrm{D}} / I_{\mathrm{G}}=1.54\right)$ and TEM image.
Then we introduced PCNTs and CCNTs in PA6 via melt mixing method. DSC results showed that the crystallization temperature shifted to a higher temperature by incorporating both types of CNTs. CNTs act as nucleating agent and their thermal conductivity affect this operation. More than $30 \%$ increase in crystallinity detected for PA6/PCNTs nanocomposites. XRD patterns of nanocomposites showed that crystalline structure of PA6 has changed from $\alpha / \gamma$ phase to more thermodynamically stable $\alpha$-form. Melting point of nanocomposites showed narrower range due to high thermal conductivity of CNTs. Thermal degradation behaviour of all nanocomposites was the same as neat PA6. Decomposition temperature at $5 \mathrm{wt} \%$ under $\mathrm{N}_{2}$ atmosphere enhanced by increasing CNTs loading. PCNTs had more impact on changing the thermal and crystalline properties of PA6 compared to CCNTs due to higher metal contents since this metal can facilitate heat conduction and therefore could help mobility or the decomposition of polymer chains. Tensile tests showed unmodified non-polar CNTs do not have any affinity and interfacial interaction with polar polyamide chains and hence, no significant improvement observed in mechanical properties.

\section{Acknowledgements}

The authors wish to acknowledge the financial support provided by Malaysian Technology Development Corporation (MTDC) (project no. 6053013) and RU grant (No. 814004).

\section{References}

[1] Iijima S.: Helical microtubules of graphitic carbon. Nature, 354, 56-58 (1991). DOI: $10.1038 / 354056 \mathrm{a} 0$

[2] Zhao C., Hu G., Justice R., Schaefer D. W., Zhang S., Yang M., Han C.: Synthesis and characterization of multi-walled carbon nanotubes reinforced polyamide 6 via in situ polymerization. Polymer, 46, 5125-5132 (2005).

DOI: $10.1016 /$ j.polymer.2005.04.065

[3] Chen E-C., Wu T-M.: Isothermal and nonisothermal crystallization kinetics of nylon 6/functionalized multiwalled carbon nanotube composites. Journal of Polymer Science Part B: Polymer Physics, 46, 158-169 (2008).

DOI: 10.1002/Polb.21351

[4] Liu T., Phang I. Y., Shen L., Chow S. Y., Zhang W-D.: Morphology and mechanical properties of multiwalled carbon nanotubes reinforced nylon- 6 composites. Macromolecules, 37, 7214-7222 (2004).

DOI: $10.1021 / \mathrm{Ma} 049132 \mathrm{t}$ 
[5] Pavlidou S., Papaspyrides C.: A review on polymerlayered silicate nanocomposites. Progress in Polymer Science, 33, 1119-1198 (2008).

DOI: $10.1016 /$ j.progpolymsci.2008.07.008

[6] De Zhang W., Shen L., Phang I. Y., Liu T.: Carbon nanotubes reinforced nylon-6 composite prepared by simple melt-compounding. Macromolecules, 37, 256259 (2004).

DOI: $10.1021 / \mathrm{Ma} 035594 \mathrm{f}$

[7] Xia H., Wang Q., Qiu G.: Polymer-encapsulated carbon nanotubes prepared through ultrasonically initiated in situ emulsion polymerization. Chemistry of Materials, 15, 3879-3886 (2003).

DOI: $10.1021 / \mathrm{Cm} 0341890$

[8] Gao J., Itkis M. E., Yu A., Bekyarova E., Zhao B., Haddon R. C.: Continuous spinning of a single-walled carbon nanotube-nylon composite fiber. Journal of the American Chemical Society, 127, 3847-3854 (2005). DOI: $10.1021 / \mathrm{Ja} 0446193$

[9] Zhang R. H., Yang Y. K., Xie X. L., Li R. K. Y.: Dispersion and crystallization studies of hyper-branched poly(urea-urethane)s-grafted carbon nanotubes filled polyamide-6 nanocomposites. Composites Part A: Applied Science and Manufacturing, 41, 670-677 (2010).

DOI: 10.1016/j.compositesa.2010.01.017

[10] Rangari V. K., Yousuf M., Jeelani S., Pulikkathara M. X., Khabashesku V. N.: Alignment of carbon nanotubes and reinforcing effects in nylon-6 polymer composite fibers. Nanotechnology, 19, 245703/1-245703/9 (2008).

DOI: $10.1088 / 0957-4484 / 19 / 24 / 245703$

[11] Pötschke P., Bhattacharyya A. R., Alig I., Dudkin S. M., Leonhardt A., Täschner C., Ritschel M., Roth S., Hornbostel B., Cech J.: Dispersion of carbon nanotubes into thermoplastic polymers using melt mixing. AIP Conference Proceedings, 723, 478-482 (2004).

DOI: $10.1063 / 1.1812133$

[12] Zhao X., Ye L.: Structure and mechanical properties of polyoxymethylene/multi-walled carbon nanotube composites. Composites Part B: Engineering, 42, 926933 (2011).

DOI: 10.1016/j.compositesb.2011.01.002

[13] Brosse A-C., Tencé-Girault S., Piccione P. M., Leibler L.: Effect of multi-walled carbon nanotubes on the lamellae morphology of polyamide-6. Polymer, 49, 4680-4686 (2008). DOI: $10.1016 /$ j.polymer.2008.08.003

[14] Phang I. Y., Ma J., Shen L., Liu T., Zhang W-D.: Crystallization and melting behavior of multi-walled carbon nanotube-reinforced nylon-6 composites. Polymer International, 55, 71-79 (2006).

DOI: $10.1002 /$ Pi.1920

[15] Sun L., Yang J-T., Lin G-Y., Zhong M-Q.: Crystallization and thermal properties of polyamide 6 composites filled with different nanofillers. Materials Letters, 61, 3963-3966 (2007).

DOI: $\underline{10.1016 / \text { j.matlet.2006.12.090 }}$
[16] Zein S. H. S., Mohamed A. R., Sai P. S. T.: Kinetic studies on catalytic decomposition of methane to hydrogen and carbon over $\mathrm{Ni} / \mathrm{TiO}_{2}$ catalyst. Industrial and Engineering Chemistry Research, 43, 4864-4870 (2004).

DOI: $10.1021 / \mathrm{ie} 034208 \mathrm{f}$

[17] Chai S-P., Lee K-Y., Ichikawa S., Mohamed A. R.: Synthesis of carbon nanotubes by methane decomposition over $\mathrm{Co}-\mathrm{Mo} / \mathrm{Al}_{2} \mathrm{O}_{3}$ : Process study and optimization using response surface methodology. Applied Catalysis A: General, 396, 52-58 (2011).

DOI: 10.1016/j.apcata.2011.01.038

[18] Sivakumar V. M., Abdullah A. Z., Mohamed A. R., Chai S. P.: Optimized parameters for carbon nanotubes synthesis over Fe and Ni catalyst via methane CVD. Reviews on Advanced Materials Science, 27, 25-30 (2011)

[19] Yeoh W-M., Lee K-Y., Chai S-P., Lee K-T., Mohamed A. R.: Synthesis of high purity multi-walled carbon nanotubes over $\mathrm{Co}-\mathrm{Mo} / \mathrm{MgO}$ catalyst by the catalytic chemical vapor deposition of methane. New Carbon Materials, 24, 119-123 (2009). DOI: $10.1016 / \mathrm{S} 1872-5805(08) 60041-4$

[20] Liu X., Wu Q., Berglund L. A., Qi Z.: Investigation on unusual crystallization behavior in polyamide 6/montmorillonite nanocomposites. Macromolecular Materials and Engineering, 287, 515-522 (2002).

DOI: $10.1002 / 1439-2054(20020801) 287: 8<515$ ::aidmame515>3.0.co;2-b

[21] Chow W. S., Mohd Ishak Z. A., Karger-Kocsis J., Apostolov A. A., Ishiaku U. S.: Compatibilizing effect of maleated polypropylene on the mechanical properties and morphology of injection molded polyamide 6/polypropylene/organoclay nanocomposites. Polymer, 44, 7427-7440 (2003).

DOI: 10.1016/j.polymer.2003.09.006

[22] Ha H., Kim S. C., Ha K.: Morphology and properties of polyamide/multi-walled carbon nanotube composites. Macromolecular Research, 18, 660-667 (2010). DOI: $10.1007 / \mathrm{s} 13233-010-0702-\mathrm{y}$

[23] Fornes T. D., Paul D. R.: Crystallization behavior of nylon 6 nanocomposites. Polymer, 44, 3945-3961 (2003). DOI: $10.1016 / \mathrm{S} 0032-3861(03) 00344-6$

[24] Cuentas-Gallegos A. K., Miranda-Hernández M., Vargas-Ocampo A.: Dispersion effect of Cs-PW particles on multiwalled carbon nanotubes and their electrocatalytic activity on the reduction of bromate. Electrochimica Acta, 54, 4378-4383 (2009). DOI: $10.1016 /$ j.electacta.2009.03.010

[25] Cuentas-Gallegos A., Jimenez-Penaloza S., BaezaRostro D., German-Garcia A.: Influence of the functionalization degree of multiwalled carbon nanotubes on the immobilization of polyoxometalates and its effect on their electrochemical behavior. Journal of New Materials for Electrochemical Systems, 13, 369376 (2010). 
[26] Sahoo N. G., Cheng H. K. F., Cai J., Li L., Chan S. H., Zhao J., Yu S.: Improvement of mechanical and thermal properties of carbon nanotube composites through nanotube functionalization and processing methods. Materials Chemistry and Physics, 117, 313-320 (2009). DOI: 10.1016/j.matchemphys.2009.06.007

[27] Zhang F., Zhou L., Xiong Y., Liu G., Xu W.: Isothermal crystallization kinetics of high-flow nylon 6 by differential scanning calorimetry. Journal of Applied Polymer Science, 111, 2930-2937 (2009). DOI: $10.1002 / A p p .29352$

[28] Li J., Fang Z., Zhu Y., Tong L., Gu A., Liu F.: Isothermal crystallization kinetics and melting behavior of multiwalled carbon nanotubes/polyamide- 6 composites. Journal of Applied Polymer Science, 105, 35313542 (2007).

DOI: $10.1002 / A p p .24606$

[29] Liu T., Tjiu W. C., He C., Na S. S., Chung T-S.: A processing-induced clay dispersion and its effect on the structure and properties of polyamide 6. Polymer International, 53, 392-399 (2004).

DOI: $10.1002 /$ pi.1359

[30] Shen Z., Bateman S., Wu D. Y., McMahon P., Dell'Olio M., Gotama J.: The effects of carbon nanotubes on mechanical and thermal properties of woven glass fibre reinforced polyamide-6 nanocomposites. Composites Science and Technology, 69, 239-244 (2009). DOI: $10.1016 /$ j.compscitech.2008.10.017
[31] Kuan H-C., Ma C-C. M., Chang W-P., Yuen S-M., Wu H-H., Lee T-M.: Synthesis, thermal, mechanical and rheological properties of multiwall carbon nanotube/ waterborne polyurethane nanocomposite. Composites Science and Technology, 65, 1703-1710 (2005). DOI: 10.1016/j.compscitech.2005.02.017

[32] Zhu B-K., Xie S-H., Xu Z-K., Xu Y-Y.: Preparation and properties of the polyimide/multi-walled carbon nanotubes (MWNTs) nanocomposites. Composites Science and Technology, 66, 548-554 (2006). DOI: 10.1016/j.compscitech.2005.05.038

[33] Zhao F., Huang Y.: Preparation and properties of polyhedral oligomeric silsesquioxane and carbon nanotube grafted carbon fiber hierarchical reinforcing structure. Journal of Materials Chemistry, 21, 2867-2870 (2011). DOI: 10.1039/C0JM03919E

[34] Li Q., Xue Q., Hao L., Gao X., Zheng Q.: Large dielectric constant of the chemically functionalized carbon nanotube/polymer composites. Composites Science and Technology, 68, 2290-2296 (2008).

DOI: $10.1016 /$ j.compscitech.2008.04.019

[35] Meng H., Sui G. X., Fang P. F., Yang R.: Effects of acid- and diamine-modified MWNTs on the mechanical properties and crystallization behavior of polyamide 6. Polymer, 49, 610-620 (2008).

DOI: 10.1016/j.polymer.2007.12.001

[36] Meng H., Sui G. X., Xie G. Y., Yang R.: Friction and wear behavior of carbon nanotubes reinforced polyamide 6 composites under dry sliding and water lubricated condition. Composites Science and Technology, 69, 606-611 (2009).

DOI: $10.1016 /$ j.compscitech.2008.12.004 